\title{
Medical and Pharmacy Students' Perceptions Regarding Generic Medicines in Yemen
}

\author{
Ahmed Al-mohamadi ${ }^{1 *}$,Abdulsalam M. Halboup', Mohamed Izham Mohamed Ibrahim ${ }^{2}$, Mahfoudh Abdulghani ${ }^{4}$, \\ Yaser Mohammed Al-Worafi' ${ }^{1,3}$, Gamil Otham ${ }^{1}$, Mohammed Alshakka ${ }^{5}$, Mukhtar Ansari ${ }^{6}$ \\ ${ }^{1}$ Department of Clinical Pharmacy and Pharmacy Practice, Faculty of Pharmacy, University of Science and Technology, \\ Sana'a, REPUBLIC OF YEMEN. \\ ${ }^{2}$ Professor, College of Pharmacy, Qatar University, Doha, QATAR. \\ ${ }^{3}$ Clinical Pharmacy Department, Ajman University, Ajman, UAE. \\ ${ }^{4}$ Department of Pharmacologyand Toxicology, Unaizah College of Pharmacy, Qassim University, Unaizah, 51911, Al Qassim, \\ SAUDI ARABIA. \\ ${ }^{5}$ Section of Clinical Pharmacy, Faculty of Pharmacy, Aden University, REPUBLIC OF YEMEN. \\ ${ }^{6}$ Department of Clinical Pharmacy, College of Pharmacy, University of Hail, Hail, SAUDI ARABIA.
}

Received: 12 February 2018;

Accepted: 27 April 2018

*Correspondence to:

Dr. Ahmed Al-mohamadi, Department of Clinical Pharmacy and Pharmacy Practice, Faculty of Pharmacy, University of Science and Technology, Sana'a, REPUBLIC OF YEMEN.

Email: a.mansor@ust.edu

Copyright: (c) the author(s),publisher and licensee Indian Academy of Pharmacists. This is an open-access article distributed under the terms of the Creative Commons Attribution Non-Commercial License, which permits unrestricted non-commercial use, distribution, and reproduction in any medium, provided the original work is properly cited.

\begin{abstract}
Objective: The study is to evaluate Yemeni medical and pharmacy students' knowledge and attitude regarding generic medicines. Method: A cross-sectional survey was used to collect data from final-year medical and pharmacy students at six public and private universities in Yemen. The questionnaire was distributed among the students through their course coordinators. Students were clearly informed about the objective of the study and their written consents were taken before the survey. The responses were entered in SPSS, and descriptive and inferential analyses were carried out. Results: The response rate was $60.1 \%$. Overall the half of participants' perception regarding generic medicine was positive. Perceptions of pharmacy students' regarding generic medicines were better than those of the medical students. Conclusion: The present study concluded that both studied groups had insufficient knowledge about quality, safety and bioequivalence of generic medicines. The medical students showed poorer knowledge than pharmacy students which need to give more attention from educators regarding the use of generic medicines.
\end{abstract}

Key words: Generic drugs, Medical students, Perception, Pharmacy students, Yemen.

\section{INTRODUCTION}

Generic medicine is not inferior than innovative or branded medicine and thus it can be substitutable with an innovative/branded medicine..$^{[1]}$ The main purpose of introducing the idea of generic medicine was to reduce escalating health care costs and to improve the access of public to essential medicine. ${ }^{[2-3]}$ The high price of branded medicines was reported as the main barrier toward access to the medicines, mainly in developing countries. ${ }^{[4]}$ Yemen is among the lowest country on annual health expenditure. ${ }^{[5]}$ In such a scenario like Yemen, it is highly desirable to encourage the use of generic medicines throughout the nation. Physicians and pharmacists can play influential role in this regard through prescribing and dispensing generic medicines respectively, provided they should work collectively. ${ }^{\left[{ }^{6}\right]}$ But, there is controversial perception regarding bioequivalence, safety, and quality of generic medicines ${ }^{[7]}$ which affect prescribing attitude of physicians ${ }^{[8]}$ and dispensing behaviour of practising pharmacists..$^{[9]}$ This problem can be downgraded by providing educational interventions about the benefits of generic prescribing to the prescribers, dispensers, medical students, and pharmacy students. There are limited studies in the low- and middle-income countries on the assessment and comparison of the knowledge and perception of final year medical and pharmacy students regarding generic medicine and brand substitution. In near future, final year medical and pharmacy students would become the registered professionals. Thus, their knowledge and perception at this level would reflect their future practice, in term of prescribing and dispensing, of generic medicines. ${ }^{[8-9]}$ In Southeast Yemen, knowledge, attitudes, and perceptions of pharmacy and medical students were assessed, and the finding revealed that those students had knowledge deficit regarding generic medicines' bioequivalence, safety, and quality. ${ }^{[10]}$ The findings of this study can be considered as a point of reference for legislation, policy makers, pharmacy and medical schools and future healthcare professionals in Yemen. The objective of the study is to evaluate Yemeni medical and pharmacy students' knowledge and attitude regarding generic medicines.

\section{METHODS}

A cross-sectional survey was used to collect data from medical and pharmacy students at six public and private universities in Yemen in 2013. This study was approved from the ethical research committee in the University of Science and Technology, Sana'a, Yemen. Anonymity and confidentiality for all participants were ensured. Participation Consent was implied by the completion and return of the survey.

Data were collected using pre-tested questionnaire. ${ }^{[4]}$ The Questionnaire used in the survey was divided into two sections. The first section comprised demographic variables including student's nationality, age, gender, and type of scholarship and university. The second section was further divided into 
three set of questions, the first part was concerned with student's knowledge and perception regarding generic medicine, the second part was concern with student' perception regarding quality, safety of generic medicines versus brand-name, and the third part was concerned with current education background of medical and pharmacy students about generic medicines. The questions in the second section were formatted into a five-point Likert-scale (i.e. $1=$ strongly disagree, $2=$ disagree, $3=$ neutral, $4=$ agree, and $5=$ strongly agree). Content validity of the questionnaire, including relevance, clarity, and conciseness of the questions were evaluated by experts. Experts' comments and observations were considered in the final form of the questionnaire.

Data was gathered from all medical and pharmacy students at three public and three private universities in Sana'a Yemen. The sampling criteria included all sixth year medical students and fifth year pharmacy students who were registered as full-time student at three public and three private universities during the study period $(\mathrm{N}=608)$. The number and list of registered students were obtained from the respective lecturer coordinators in each of the universities. Subjects of the study were informed about the objective of the survey through an explanatory letter attached to the survey questionnaire. The questionnaire was distributed among the students through the respective academic coordinators of their universities.

Respondents' demographic information, such as frequencies and percentages was represented using descriptive statistical analyses. Association between categorical variables were assessed using Chi-square test. A statistical significance level was set at $\mathrm{P}<0.05$.

\section{RESULTS}

Three hundred sixty five $(60.1 \%)$ out of 608 students who had received the questionnaires completed the questionnaire. Among the respondents, 165 $(45 \%)$ were medical students and 200 (55\%) were pharmacy students (Table 1). The students with age 23 or more were $297(81.4 \%$ ), and the students with age less than 23 were $68(18.6 \%)$. A total of $239(65.5 \%)$ of the participants were male compared with female students who comprised $126(34.5 \%)$ of the participants.

Three questions were used to evaluate the students' knowledge and perception about generic equivalence (Table 2). Compare to medical students, high percentage of pharmacy students (54\% and $48.5 \%$ ) correctly responded that the agents that are evaluated as generic equivalent are considered therapeutically equivalent to each other and to innovator brand product, respectively. Also, most of the pharmacy students (79.5\%) reported their desire to know more information on how to conduct bioequivalence tests. Significant associations between medical and pharmacy profession and their all responses were detected as shown in Table 2, table 3 and table 4.

Regarding respondents' perception about quality and safety of a generic medicine compared with its brand-name, five items were used (Table 3). Higher

\begin{tabular}{|l|l|l|l|}
\hline \multicolumn{4}{|l|}{ Table 1: Respondents' Demographic Data. } \\
\hline Demographic Data & & Freq. & $\%$ \\
\hline Group & Medical students & 165 & 45.2 \\
\hline & Pharmacy students & 200 & 54.8 \\
\hline Age & Less than 23 & 68 & 18.6 \\
\hline & 23 or more & 297 & 81.4 \\
\hline Gender & Male & 239 & 65.5 \\
\hline & Female & 126 & 34.5 \\
\hline Nationality & Yemeni & 307 & 84.1 \\
\hline & Others & 58 & 15.9 \\
\hline Scholarship & Government & 185 & 50.7 \\
\hline & Private & 143 & 39.2 \\
\hline & Others & 37 & 10.1 \\
\hline University response rate & Government & 247 & 67.7 \\
\hline & Private & 118 & 32.3 \\
\hline
\end{tabular}

percentage of pharmacy students $(74.5 \%, 74 \%$; respectively) understood that the dosage form and dose strength of a generic medicine must be the same as its brand-name medicine. Almost one third of pharmacy students $(35 \%)$ thought that generic medicine produces side effects more than that of brand name medicine; this percentage was less with medical students $(18.8 \%)$. High percentage of medical students $(78.8 \%)$ disagreed that the generic medicine is less expensive than brand name medicine; this issue was less with pharmacy students $(10 \%)$.

In the last part, three items were used to assess the students' perception regarding current education about generic medicines (Table 4). A high percentage of pharmacy students $(80 \%)$ agreed that they need more information regarding issues belonging to generic medicines' safety and efficacy compared with $13.9 \%$ of medical students. The majority of pharmacy students $(75.5 \%)$ agreed that they have the confidence to substitute generic medicine for its brand-name; additionally, high percentage of pharmacy students $(62.5 \%)$ agreed that it is easier to recall the generic names of drug rather than the brand names. Compared with pharmacy students, most medical students $(44.9 \%)$ disagreed with substituting the innovator brand by a generic product. also, most of them (47.3\%) disagreed that the generic name is easier than the brand names to recall medicine's therapeutic class.

\section{DISCUSSION}

The attempted objective was to asses and compare knowledge and perception of final year medical and pharmacy students about generic medicines. The current study showed statistically significant difference between medical and pharmacy students regarding the medicines that were rated as generic equivalent should be considered as therapeutically equivalent to each other and to their corresponding brand-name medicines.

\section{Table 2: Knowledge and perception of generic equivalent medicine.}

\begin{tabular}{|c|c|c|c|c|c|c|c|c|}
\hline \multicolumn{2}{|l|}{ Statement } & \multirow{2}{*}{$\begin{array}{l}\text { SD } \\
7.0 \%\end{array}$} & \multirow{2}{*}{$\begin{array}{l}\text { D } \\
18.0 \%\end{array}$} & \multirow{2}{*}{$\begin{array}{l}\mathbf{N} \\
26.5 \%\end{array}$} & \multirow{2}{*}{$\begin{array}{l}\mathbf{A} \\
36.5 \%\end{array}$} & \multirow{2}{*}{$\begin{array}{l}\text { SA } \\
12.0 \% \\
\end{array}$} & \multirow{2}{*}{$\begin{array}{l}\text { Chi-square } \\
28.9\end{array}$} & \multirow{2}{*}{$\begin{array}{l}\text { p-value } \\
<0.001\end{array}$} \\
\hline A generic medicine that is rated as "generic equivalent" & Pharmacy & & & & & & & \\
\hline & Medicine & $9.7 \%$ & $41.2 \%$ & $21.2 \%$ & $21.8 \%$ & $6.1 \%$ & & \\
\hline \multirow{2}{*}{$\begin{array}{l}\text { Generic medicines that are rated as "generic } \\
\text { equivalents" are therapeutically equivalent to each other. }\end{array}$} & Pharmacy & $7.5 \%$ & $17.5 \%$ & $21.0 \%$ & $39.5 \%$ & $14.5 \%$ & 47.8 & \multirow[t]{2}{*}{$<0.001$} \\
\hline & Medicine & $7.9 \%$ & $43.6 \%$ & $27.3 \%$ & $17.0 \%$ & $4.2 \%$ & & \\
\hline \multirow{2}{*}{$\begin{array}{l}\text { I need more information on how to conducted } \\
\text { bioequivalence tests for a generic product }\end{array}$} & Pharmacy & $1.5 \%$ & $6.0 \%$ & $13.0 \%$ & $29.0 \%$ & $50.5 \%$ & 221.4 & \multirow[t]{2}{*}{$<0.001$} \\
\hline & Medicine & $41.2 \%$ & $38.8 \%$ & $11.5 \%$ & $7.9 \%$ & $0.6 \%$ & & \\
\hline
\end{tabular}

Total number of pharmacy students $=200$, medical students $=165$.

$\mathrm{SD}=$ strongly disagree, $\mathrm{D}=$ disagree, $\mathrm{N}=$ neutral, $\mathrm{A}=$ agree, and $\mathrm{SA}=$ strongly agree. 


\begin{tabular}{|c|c|c|c|c|c|c|c|c|}
\hline \multicolumn{2}{|l|}{ Statement } & \multirow{2}{*}{$\begin{array}{l}\text { SD } \\
6.5 \%\end{array}$} & \multirow{2}{*}{$\begin{array}{l}\text { D } \\
21.5 \% \\
\end{array}$} & \multirow{2}{*}{$\begin{array}{l}\mathbf{N} \\
9.0 \% \\
\end{array}$} & \multirow{2}{*}{$\begin{array}{l}\mathbf{A} \\
52.5 \% \\
\end{array}$} & \multirow{2}{*}{$\begin{array}{l}\text { SA } \\
10.5 \% \\
\end{array}$} & \multirow{2}{*}{$\begin{array}{l}\text { Chi-square } \\
22.1\end{array}$} & \multirow{2}{*}{$\begin{array}{l}\boldsymbol{p} \text {-value } \\
<0.001\end{array}$} \\
\hline A generic medicine is bioequivalent to its innovator brand & Pharmacy & & & & & & & \\
\hline & Medicine & $6.7 \%$ & $20.6 \%$ & $26.1 \%$ & $37.0 \%$ & $9.7 \%$ & & \\
\hline \multirow{2}{*}{$\begin{array}{l}\text { The dosage form of generic medicine must be the same as that of } \\
\text { brand name medicine (e.g. tablet, capsule) }\end{array}$} & Pharmacy & $2.5 \%$ & $13.0 \%$ & $10.0 \%$ & $42.0 \%$ & $32.5 \%$ & 141.1 & \multirow[t]{2}{*}{$<0.001$} \\
\hline & Medicine & $20.0 \%$ & $40.0 \%$ & $26.1 \%$ & $11.5 \%$ & $2.4 \%$ & & \\
\hline \multirow{2}{*}{$\begin{array}{l}\text { Dose strength of a generic medicine must equal that of brand } \\
\text { name. }\end{array}$} & Pharmacy & $6.5 \%$ & $9.0 \%$ & $10.5 \%$ & $30.5 \%$ & $43.5 \%$ & 138.1 & \multirow[t]{2}{*}{$<0.001$} \\
\hline & Medicine & $29.7 \%$ & $30.9 \%$ & $25.5 \%$ & $10.9 \%$ & $3.0 \%$ & & \\
\hline \multirow{2}{*}{$\begin{array}{l}\text { Generic medicines are expected to produce more side-effects } \\
\text { than brand name medicines. }\end{array}$} & Pharmacy & $9.0 \%$ & $29.0 \%$ & $27.0 \%$ & $21.0 \%$ & $14.0 \%$ & 14.1 & \multirow[t]{2}{*}{0.007} \\
\hline & Medicine & $14.5 \%$ & $31.5 \%$ & $35.2 \%$ & $13.3 \%$ & $5.5 \%$ & & \\
\hline \multirow{2}{*}{$\begin{array}{l}\text { Generic medicines are expected to be less expensive than brand } \\
\text { name medicines. }\end{array}$} & Pharmacy & $2.5 \%$ & $7.5 \%$ & $7.0 \%$ & $33.5 \%$ & $49.5 \%$ & 226.8 & \multirow[t]{2}{*}{$<0.001$} \\
\hline & Medicine & $41.8 \%$ & $37.0 \%$ & $10.9 \%$ & $8.5 \%$ & $1.8 \%$ & & \\
\hline
\end{tabular}

Total number of pharmacy students $=200$, medical students $=165$

$\mathrm{SD}=$ strongly disagree, $\mathrm{D}=$ disagree, $\mathrm{N}=$ neutral, $\mathrm{A}=$ =agree, and $\mathrm{SA}=$ strongly agree.

\begin{tabular}{|l|l|l|l|l|l|l|l|}
\hline Table 4: Perception of current education regarding generic medicines. \\
\hline Statement & SD & D & N & A & SA & Chi-square & p-value \\
\hline $\begin{array}{l}\text { I need more information on the issues related to generic medicines' } \\
\text { safety and efficacy. }\end{array}$ & Pharmacy & $1.0 \%$ & $7.5 \%$ & $11.5 \%$ & $29.5 \%$ & $50.5 \%$ & 191.5 \\
\cline { 2 - 9 } & Medicine & $32.1 \%$ & $39.4 \%$ & $14.5 \%$ & $11.5 \%$ & $2.4 \%$ & \\
\hline $\begin{array}{l}\text { From the knowledge I have, I have the confidence to substitute an } \\
\text { brand-name by its generic medicine }\end{array}$ & Pharmacy & $2.5 \%$ & $10.5 \%$ & $11.5 \%$ & $47.5 \%$ & $28.0 \%$ & 91.4 \\
\cline { 2 - 9 } & Medicine & $15.8 \%$ & $29.1 \%$ & $27.9 \%$ & $22.4 \%$ & $4.8 \%$ & \\
\hline $\begin{array}{l}\text { It is easier to recall the class of medicine using generic names rather } \\
\text { than brand names. }\end{array}$ & Pharmacy & $4.0 \%$ & $16.5 \%$ & $17.0 \%$ & $45.5 \%$ & $17.0 \%$ & 64.1 \\
\cline { 2 - 9 } & Medicine & $10.3 \%$ & $37.0 \%$ & $30.9 \%$ & $12.1 \%$ & $9.7 \%$ & \\
\hline
\end{tabular}

Total number of pharmacy students $=200$, medical students $=165$

$\mathrm{SD}=$ strongly disagree, $\mathrm{D}=$ disagree, $\mathrm{N}=$ neutral, $\mathrm{A}=$ agree, and $\mathrm{SA}=$ strongly agree.

These findings may be justified by possible differences in the educational background and training received during their education. The result in this study agreed with the finding reported by previous studies. ${ }^{[11-12]}$ Moreover, Siam et al. reported that there was a significant difference among pharmacy and medical students regarding knowledge of generic medicine in Bangladesh. ${ }^{[4]}$ In contrast, a study conducted by Basak and Sathyanarayana in India showed that many of the pharmacists and drug retailers have misconception regarding generic medicines, and they lack enough knowledge about generic substitution, even if the prescribed medicines are not available. ${ }^{[13]}$

High proportion of medical students pointed that they do not need more information on conducting bioequivalence tests. This was in contrast with the reports by Das and Das and Hassali et al. ${ }^{[14,11]}$ but it may reflect misunderstanding of medical students about the importance of such courses. On the other hand, pharmacy students were eager to accept more information when it was offered to them; especially, when a topic was more related to pharmacy curriculum.

There was a significant difference among pharmacy and medical students about the perception on generic medicine and its bioequivalence to the corresponding brand-name medicines. Medical students thought that the dosage form of a generic medicine is not required to be the same as its corresponding brand-name medicine. This result is consistent with other studies conducted in South Yemen by Al-Tamimi et al. ${ }^{[10]}$ and in Australia by Hassali et al. ${ }^{[1]}$ which highlighted the issue probably due to their less education on drug formulation compared with pharmacists. Regarding medication dose, pharmacy students were more aware than medical students that the dose strength of a generic medicine must be the same as its corresponding brand-name medicine. As previously justified, some courses such as pharmaceutics and clinical pharmacy are not addressed at medical schools' curricula and this might be anticipated to have impact on the medical students' responses regarding such question.

Pharmacy students pointed that a generic medicine costs less that its corresponding brand-name; however, medical students denied. This knowledge can be attributed to the students who had training in community or hospital pharmacies are more experienced in terms of pricing than medical students. This issue is supported by what has been found in Australia by Hassali et al. ${ }^{[1]}$

Medical students do not prefer to have more information about generic medicines' safety and efficacy. These responses obviously showed deficit perception about the current medical education, and importance of such courses in future practice. A nationwide study conducted in Malaysia also supports this finding. The findings of the study showed a negative perception of physicians regarding quality, safety, and efficacy of generic medicines. ${ }^{[15]}$ Another study by Gyawali et al. in Nepal also go along with this. ${ }^{[16]}$ But, the study conducted in Afghanistan by Bashaar et al. found the opposite. ${ }^{[17]}$

Pharmacy students responded that it is easier for them to identify the class of certain drug using the generic names rather than the brand names. This can be attributed mainly to the extensive use of generic names in pharmacy education and the practice of such names during community and hospital pharmacies practice.

The present study concludes that both groups have knowledge deficit regarding some issues, specifically on some issues of quality and safety of generic medicines; however, medical students show poorer knowledge than pharmacy students. These area of deficits need to be addressed by 
educator of both groups and the value of generic medicines warranted to be discussed with future practitioners.

\section{Limitations}

One of the main drawbacks of this study is that a convenience sample was used to draw study respondents. In addition, this study did not consider the relationship between the curriculum content for both groups and the perception about the use the generic medicines. Furthermore, only three out of ten medical schools were included in this study. Similarly, from more than 15 public and private pharmacy schools, only 5 pharmacy schools were included. Further study are suggested to focus on such limitation in order to detect the obstacle that may result in negative perception regarding generic medicines use.

\section{ACKNOWLEDGEMENT}

None.

\section{CONFLICT OF INTEREST}

The authors declare no conflict of interest

\section{REFERENCES}

1. WHO: Glossary of globalization, trade and health terms. Secondary Glossary of Globalization, Trade and Health Terms. Available from; http://www.who int/ trade/glossary/story021/en/

2. Bissell K, Perrin C, Beran D. Access to essential medicines to treat chronic respiratory disease in low-income countries. Int $\mathrm{J}$ Tuberc Lung Dis. 2016;20(6):717-28.

3. Minhas R, Ng JC, Tan J, Wu H, Pro SS, Beach J, et al. Should Developed Countries, Including Canada, Provide Universal Access to Essential Medications through a National, Publicly Funded and Administered Insurance Plan? Can J Hosp Pharm.2016;69(2).

4. Siam MK, Khan A, Khan TM. Medical and pharmacy students' knowledge and perceptions about generic medicines in Bangladesh. J Pharm Health Serv Res. 2013;4(1):57-61.

5. Al-Tamimi SK, Hassali M, Alrasheedy AA, Challenges to generic medicines utilization in Yemeni healthcare system. GABI J. 2013;2(2):63-4.
6. Massard da Fonseca E, Shadlen KC. Promoting and regulating generic medicines: Brazil in comparative perspective. Rev Panam Salud Publica. 2017;41:e5.

7. Bate R, Mathur A, Lever HM, Thakur D, Graedon J, Cooperman T, et al. Generics substitution, bioequivalence standards, and international oversight: complex issues facing the FDA. Trends Pharmacol Sci. 2016;37(3):184-91.

8. Othman GQ, Abdulghani MA, AlHyfi HA, Alkhazzan A, Al-Qadasi F. Knowledge and Perceptions of Final-Year Medical Students in Yemeni Universities about Generic Medicines. Yemeni J Med Sci. 2016;10:15-23.

9. Othman GQ, Abdulghani MA. Assessment of knowledge and perceptions of generic medicines among pharmacy students in Yemeni universities. Pharmacy Education. 2015; 15.

10. AL-Tamimi S, Hassali M, Shafie A, Alrasheedy A. Comparision Of Perception Towrds Generic Medicines Between Final Year Pharmacy And Medical Students In Southeast Yemen. Value in Health. 2016;19(7):A815.

11. Hassali MA, Kong D, Stewart K. A comparison between senior medical students' and pharmacy pre $\square$ registrants' knowledge and perceptions of generic medicines. Medical Education. 2007;41(7):703-10.

12. Lee SW, Hassali MA, Shafie AA. Knowledge and perception of senior year pharmacy students about generic medicines in public Universities of Malaysia. Arch Pharma Pract. 2014;5(3):108-12.

13. Basak S, Sathyanarayana D. Exploring knowledge and perceptions of generic medicines among drug retailers and community pharmacists. Indian J Pharm Sci. 2012;74(6):571.

14. Das NG, Das SK. An Approach to Pharmaceutics Course Development as the Profession Changes in the 21 st Century. Pharmacy education. 2002;1(3):159-71.

15. Kumar R, Hassali MA, Saleem F, Alrasheedy AA, Kaur N, Wong ZY, et al. Knowledge and perceptions of physicians from private medical centres towards generic medicines: A nationwide survey from Malaysia. J Pharm Policy Pract. 2015;8(1):11.

16. Gyawali S, Hassali MA, Saha A. A survey exploring the knowledge and perceptions of senior medical students in Nepal toward generic medicines. SAGE Open Med. 2016;4.

17. Bashaar M, Hassali MA, Saleem F, Shafie AA. Assessment of Medical and Pharmacy Students' Knowledge and Perceptions about Generic Medicines' Prices and Quality in Kabul-Afghanistan. 2015; J App Pharm Sci. 2015;5(8):100-4.

Cite this article as: Al-mohamadi A, Halboup AM, Ibrahim MIM, Abdulghani M, Al-Worafi YM, Otham G, Alshakka M, Ansari M. Medical and Pharmacy Students' Perceptions Regarding Generic Medicines in Yemen. J Pharm Pract Community Med. 2018;4(2):47-50. 